\title{
NMDA Receptor Antagonists Impair Prefrontal Cortex Function as Assessed via Spatial Delayed Alternation Performance in Rats: Modulation by Dopamine
}

\author{
Anita Verma and Bita Moghaddam \\ Department of Psychiatry, Yale University School of Medicine, VA Medical Center, West Haven, Connecticut 06516
}

The present study was performed to assess the role of excitatory amino acid and dopamine receptors on associative functions of the prefrontal cortex (PFC) of the rat. Spatial delayed alternation was used as a PFC-sensitive cognitive task. In addition, in vivo microdialysis was used to assess the release of dopamine in the PFC. The noncompetitive NMDA antagonists ketamine $(10-30 \mathrm{mg} / \mathrm{kg})$ and $\mathrm{MK}-801(0.1$ and $0.5 \mathrm{mg} / \mathrm{kg}$ ) dose-dependently impaired the spatial delayed alternation performance compared with the saline-treated control group. Administration of the dopamine antagonists raclopride $(0.1$ and $0.5 \mathrm{mg} / \mathrm{kg}), \mathrm{SCH}-23390(0.1 \mathrm{mg} / \mathrm{kg})$, or haloperidol $(0.1 \mathrm{mg} / \mathrm{kg})$ was without a significant effect. However, haloperidol and raclopride (but not $\mathrm{SCH}-23390$ ) re-

The prefrontal cortex (PFC) plays a vital role in mnemonic, attention, and spatial abilities (Fuster, 1980; Stuss and Benson, 1983; Goldman-Rakic, 1987). The role of the PFC in "working memory," the brief retention of internalized information that can guide behavior (Mishkin and Pribram, 1955; Goldman-Rakic, 1987, 1991; McCarthy et al., 1994), has received a great deal of attention because most patients with cognitive disorders such as schizophrenia exhibit deficits in working memory-related tasks (Taylor and Abrams, 1984; Parks and Holzman, 1992). Furthermore, abnormal metabolic activity in the PFC of patients with schizophrenia has been reported during the performance of these tasks (Weinberger et al., 1986).

A significant role for dopamine in the PFC orchestration of working memory was realized when depletion of dopamine in the dorsolateral PFC of the rhesus monkey impaired the performance of delayed alternation, a working memory-related task, as severely as surgical ablation of the same area (Brozoski et al., 1979). Furthermore, intracerebral injections of D1 dopamine receptorselective antagonists increased the error rate during delayed response tasks (Sawaguchi and Goldman-Rakic, 1991, 1994). Similarly, studies performed in the rodent have demonstrated an impairment of delayed alternation response after chemical lesions of the dopamine afferents to the medial PFC (Simon et al., 1980; Stam et al., 1989; Wilcott and Xuemei, 1990).

Another class of neurons that may play an important role in

\footnotetext{
Received June 26, 1995; revised Aug. 30, 1995; accepted Sept. 7, 1995.

Correspondence should be addressed to Bita Moghaddam, Department of Psychiatry, Yale University School of Medicine, VA Medical Center, 116A/2, West Haven, CT 06516.

This work was supported in part by USPHS Awards MH-48404 and MH-44866, Veterans Administration Merit award and Center for Schizophrenia, and the Scottish Rite Foundation. We thank Maria Bolinao for her technical assistance.

Copyright (C) 1995 Society for Neuroscience $0270-6474 / 95 / 160373-07 \$ 05,00 / 0$
}

versed the disruptive effect of $30 \mathrm{mg} / \mathrm{kg}$ ketamine on spatial delayed alternation performance. Microdialysis studies revealed that this dose of ketamine preferentially increased the release of dopamine in the PFC compared with the striatum. These findings indicate that attenuation of glutamatergic neurotransmission at the NMDA receptor impairs PFC-dependent cognitive functions. Furthermore, activation of dopamine neurotransmission contributes, at least in part, to this impairment.

Key words: prefrontal cortex; glutamate; dopamine; delayed alternation; microdialysis; NMDA receptors; schizophrenia; antipsychotic drugs

PFC function is the excitatory amino acid-containing neurons. Morphological and biochemical studies have indicated a close interaction between excitatory amino acid and dopamine afferents in the PFC (Smiley et al., 1994; Jedema and Moghaddam, in press). Furthermore, clinical studies have reported that subanesthetic doses of the noncompetitive NMDA receptor antagonist ketamine produce cognitive impairment and deficits in PFCsensitive tasks such as the Wisconsin Card Sorting test and Continuous Performance tasks (Ghoneim et al., 1985; Krystal et al., 1994). These findings implicate excitatory amino acid neurotransmission at the NMDA receptor in the proper functioning of the PFC and suggest an interaction between glutamatergic and dopaminergic systems in the modulation of spatial working memory. However, sufficient direct evidence is lacking to support these speculations.

In the present study, the role of the NMDA receptor antagonists ketamine and MK- 801 in the performance of spatial delayed alternation, a working memory task sensitive to proper functioning of the PFC (Goldman-Rakic, 1987; Stam et al., 1989), was examined in the rat. Furthermore, the role of dopamine in this paradigm was evaluated by investigating the effect of ketamine on the release of dopamine from the PFC and by examining the effect of dopamine receptor antagonists on the ability of NMDA antagonists to alter spatial delayed alternation performance.

\section{MATERIALS AND METHODS}

Animals. Adult male Sprague-Dawley rats $(250-350 \mathrm{gm})$ were used throughout this study. All animal use procedures were in accordance with the National Institutes of Health Guide for the Care and Use of Laboratory Animals and were approved by the Yale University Animal Care and Use Committee.

Spatial delayed alternation. The most commonly used behavioral tests that assess PFC-sensitive working memory in laboratory animals are delayed alternation paradigms (for review, see Goldman-Rakic, 1987). 


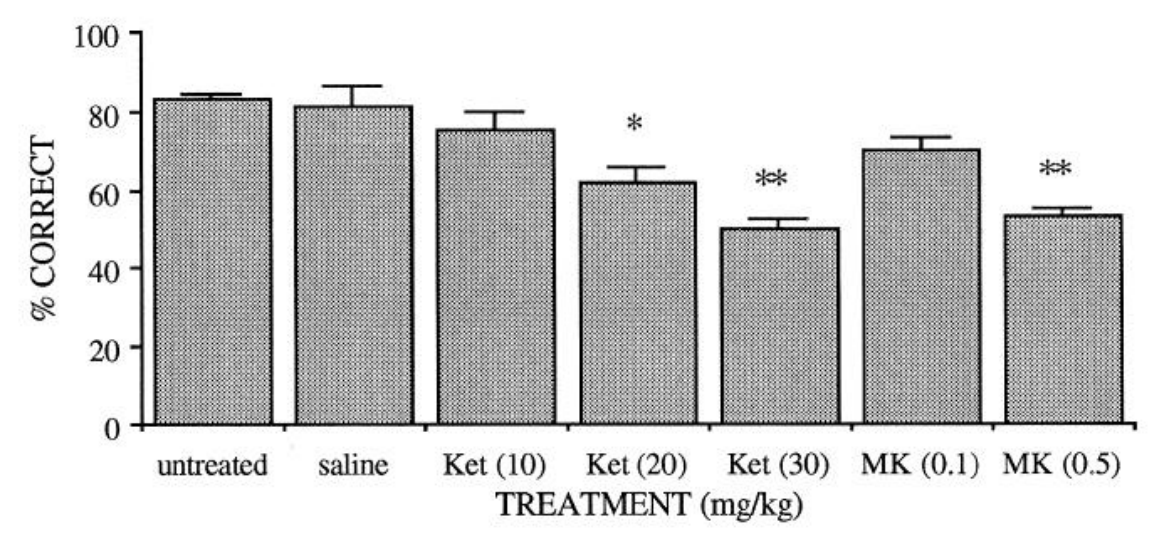

Figure 1. Effect of the noncompetitive NMDA antag onists ketamine (Ket) and MK-801 $(M K)$ on percent correct choice (mean \pm SEM) in spatial delayed alternation performance in rats. Each animal received 10 trials/d with an intertrial interval of $10 \mathrm{sec}$. The rats were trained until the criterion of $80 \%$ correct choices on two consecutive days was reached. The doses indicated in parentheses are in $\mathrm{mg} / \mathrm{kg}$. Ketamine $(20$ and $30 \mathrm{mg} / \mathrm{kg}$, i.p.) and MK-801 ( $0.5 \mathrm{mg} / \mathrm{kg}$, i.p.) produced significant decreases in percent correct responses compared with the saline-treated group $\left({ }^{*} p<0.01,{ }^{* *} p<0.001 \mathrm{com}-\right.$ pared with the saline-treated group).
These tasks impose a delay between the presentation of a cue stimulus and the performance of a motor response and are thought to assess an animal's ability to guide behavior by formation of internal representations of stimuli that are no longer present in the environment.

T-maze parameters. Spatial delayed alternation was tested in a T-maze constructed from Plexiglas and painted a medium gray. The walls were 30 $\mathrm{cm}$ high, and the alleys were $15 \mathrm{~cm}$ wide. The length of the main alley was $50 \mathrm{~cm}$, and the length of the side alleys was $40 \mathrm{~cm}$. The side alleys were closed off from the main alley by movable doors. At the end of each side alley was a 2-cm-high barrier that concealed the food reward from view. A third movable door was mounted in the main alley. A holding cage was placed adjacent to the T-maze for use during experiments with intertrial intervals. A video camera was situated $\sim 1 \mathrm{~m}$ above the T-maze to videotape the test session. The video recordings were used to measure the running time from the main arm to the goal arm. The T-maze was cleaned between different animals but not between different trials. The food reward was one morsel of Fruit Loops cereal.

Training procedure for spatial delayed alternation. Animals were handled daily for 1 week before exposure to the T-maze. On two consecutive days, each rat was allowed to explore the maze with all doors raised for $10 \mathrm{~min}$. Food was placed in both goal arms. After these two days, animals were partially food-deprived (each animal received $15 \mathrm{gm}$ of food/d) and remained that way throughout the remaining part of the experiment. After $2 \mathrm{~d}$ of food deprivation, the adaptation process continued by placing the animal in each side arm with the doors closed, with food present at the end of the alley behind the barrier, for $5 \mathrm{~min}$. The animal was then placed in the other arm, which also contained food behind the barrier, for a $5 \mathrm{~min}$ stay. This part of the adaptation procedure continued for $2 \mathrm{~d}$.

Next, the actual spatial alternation testing started. Each rat received 10 trials/d. During the first trial of each day, a Fruit Loop morsel was presented in both goal arms. During the next 10 trials, the arm opposite the one the animal had entered the previous trial was baited, except when the animal had gone to the empty arm on the last trial. In that case, the food pellet was left in place (hence, the baited side was changed only after the animal had alternated). After the animal entered either arm, the door was closed. After $(10 \mathrm{sec})$ entry to the arm, the animal was removed and returned to the holding cage for a $10 \mathrm{sec}$ intertrial interval. This training continued until a criterion of $80 \%$ correct choices (out of 10 trials) on two consecutive days was achieved. Animals took $10-14 \mathrm{~d}$ to reach the criterion. Animals that did not reach the criterion by $20 \mathrm{~d}$ were rejected from the study. In this study, $5 \%$ of rats belonged to this latter group.

Training procedure for spatial discrimination. Animals were handled and allowed to explore the maze as described above. After $2 \mathrm{~d}, 1 \mathrm{~d}$ each of food deprivation and adaptation, animals were trained to receive the food morsel only in one arm. After each trial, animals were placed back in the main alley without a delay. Each animal received 10 trials/d. The training continued daily until animals reached $80 \%$ criterion. A separate group of rats from those used for spatial delayed alternation study was used for this study.

Systemic drug injection. All drugs were injected after animals attained the $80 \%$ criterion on two consecutive days. Ketamine and SCH-23390, because of their relatively short duration of action, were injected intraperitoneally $15 \mathrm{~min}$ before testing. MK- 801 was administered $45 \mathrm{~min}$ before testing. All other drugs were injected $30 \mathrm{~min}$ before testing. The animals were placed in the holding cage for the time between injection and testing. Animals randomly received saline or a drug on the first injection. A 10-14 d interval was given between drug injections during which animals were tested 5-6 d/week. Animals received an average of four injections (10-14 d apart). These injections included at least one saline or vehicle injection and up to three drug injections, the type and dose of which were chosen randomly.

Statistical analysis. Drug- and saline-treated groups were compared by multifactorial ANOVA. Significant main effects were analyzed further by Tukey's post-hoc comparison of means.

Microdialysis. The technique of in vivo microdialysis was used to measure the extracellular levels of dopamine in the striatum and the PFC. This technique uses a dialysis probe implanted in the brain that is continuously perfused with physiological Ringer's solution or artificial cerebrospinal fluid. The collected brain perfusates are then analyzed by suitable procedures.

Microdialysis procedure. Concentric microdialysis probes with an exposed tip length of $3 \mathrm{~mm}$ were used. Probes were perfused at a flow rate of $2 \mu \mathrm{l} / \mathrm{min}$ during sample collection (probes were perfused at $0.5 \mu \mathrm{l} / \mathrm{min}$ overnight). The perfusion solution was a $2 \mathrm{~mm}$ phosphate buffer, $\mathrm{pH} 7.4$, containing the following (in mM): $145 \mathrm{NaCl}, 2.7 \mathrm{KCl}, 1.2 \mathrm{CaCl}_{2}, 1.0$ $\mathrm{MgCl}_{2}$, and 0.1 ascorbic acid. Probes were calibrated in a solution containing $10^{-7} \mathrm{M}$ dopamine. The dialysates were injected immediately onto an HPLC system with electrochemical detection for analysis of dopamine. When a stable baseline was established, animals were injected with ketamine $(30 \mathrm{mg} / \mathrm{kg})$ or saline.

Analysis of perfusate. HPLC with electrochemical detection was used for the analysis of dopamine. This system uses a narrow-bore HPLC column packed in the laboratory with $3 \mu \mathrm{m}$ of C-18 material (Phase Separations, ODS2). The mobile phase consisted of $0.05 \mathrm{~m}$ phosphate, $350 \mathrm{mg} / \mathrm{l}$ octanesulfonic acid, $300 \mu \mathrm{l} / \mathrm{l}$ triethylamine, $0.1 \mathrm{~mm}$ EDTA, and $15 \%(\mathrm{v} / \mathrm{v})$ methanol, $\mathrm{pH}$ 5.7. This mobile phase provided very clean chromatograms by moving most peaks, including dopamine metabolites, into the solvent front because of the high $\mathrm{pH}$. The electrochemical detection was carried out using a Bioanalytical Systems LC-4B. The detection limit of this system is $3-5 \mathrm{fmol} /$ injection.

Animal preparation. Microdialysis probes were implanted while rats were under halothane anesthesia. Animals were placed in a stereotaxic frame with blunt ear bars, and a small incision $(7-8 \mathrm{~mm})$ was made in the skin over the skull. The wound margin was infiltrated with lidocaine, holes were drilled for skull screws, and two microdialysis probes were aimed at the PFC (AP, +3.3; L, 0.75; V, 2.5-5.5, according to the atlas of Paxinos and Watson, 1982) and striatum (AP, +0.8; L, 2.75; V, 2.5-5.5). The screws and probe were secured in place with dental cement. Animals were allowed to recover for $24 \mathrm{hr}$ before the microdialysis measurements began.

Data analysis. The statistical comparison of the data ( $\mathrm{fmol} / \mu \mathrm{l}$ dopamine in the perfusate, not corrected for recovery) was carried out by multiway repeated-measures ANOVA.

\section{RESULTS}

\section{Effect of ketamine and MK-801 on spatial delayed alternation performance in rats}

Injection of saline, after the untreated rats had reached the criterion, failed to influence the number of correct responses (Fig. 1). Ketamine at 20 and $30 \mathrm{mg} / \mathrm{kg}$ significantly reduced the percentage of correct responses compared with the corresponding 


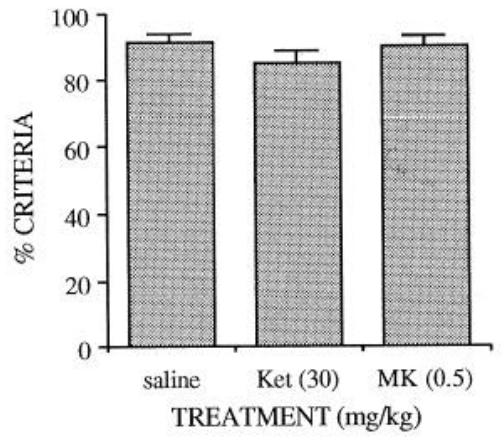

Figure 2. Effect of saline, ketamine (Ket; $30 \mathrm{mg} / \mathrm{kg}$, i.p.), and MK-801 $(M K ; 0.5 \mathrm{mg} / \mathrm{kg})$ on the performance of the spatial discrimination task. This task was performed in the same T-maze as the spatial delayed alternation; however, animals were trained to go to the same arm of the maze, without a delay, to receive a reward. In contrast to the spatial delayed alternation performance, ketamine and MK-801 did not disrupt the spatial discrimination performance.

saline-treated control group $\left(F_{(1,17)}=25.14, p<0.001, n=10\right.$ for $30 \mathrm{mg} / \mathrm{kg} ; F_{(1,12)}=6.50, p<0.05, n=8$ for $\left.20 \mathrm{mg} / \mathrm{kg}\right)$. The lower dose of ketamine $(10 \mathrm{mg} / \mathrm{kg})$ did not produce a significant decrease in the percent criteria compared with the saline-treated group $\left(F_{(1,13)}=0.66, p>0.05, n=6\right)$.

Similar to ketamine, MK-801 dose-dependently impaired spatial delayed alternation performance (Fig. 1). The percent correct choice in animals receiving MK-801 $(0.1 \mathrm{mg} / \mathrm{kg})$ was not significantly different from the saline-treated rats $\left(F_{(1,13)}=1.92, p>\right.$ $0.05, n=6)$. The higher dose of MK-801 $(0.5 \mathrm{mg} / \mathrm{kg})$, however, produced a significant decrease in percent correct choices as illustrated by the decrease in the number of errors when compared with the saline-treated rats $\left(F_{(1,13)}=12.58, p<0.001\right.$, $n=6)$.

Some behavioral stimulation including stereotyped sniffing and rearing was observed after ketamine $(10-30 \mathrm{mg} / \mathrm{kg})$ or MK-801 $(0.5 \mathrm{mg} / \mathrm{kg})$. However, the peak effect was observed $10-15 \mathrm{~min}$ after ketamine and 30-45 min after MK-801 administration, which was before testing the animals in the T-maze for spatial delayed alternation performance.

Performance in a spatial discrimination task, which did not involve alternation or delay (see Materials and Methods), was used as a control for non-PFC-dependent behaviors that may be associated with the drugs used here. Ketamine and MK-801, at doses that robustly impaired the spatial delayed alternation, did not affect the performance of the spatial discrimination task (Fig. 2).

\section{Effect of ketamine on dopamine release in the PFC}

To examine whether the dose of ketamine that potently impaired the spatial delayed alternation performance affects dopamine neurotransmission in the PFC, microdialysis in conscious rats was used (Fig. 3). After stable basal extracellular dopamine levels were obtained, animals were injected with saline or ketamine (30 $\mathrm{mg} / \mathrm{kg}$ ). Ketamine significantly increased the release of dopamine over time $(F=4.5, p<0.001, n=8)$. It should be noted that similar findings have been reported with MK 801 (Wedzony et al., 1993).

The effect of $30 \mathrm{mg} / \mathrm{kg}$ ketamine was also examined on the release of dopamine in the striatum. This treatment caused a small increase in dopamine release over time $(F=2.5, p<0.05$, $n=7$ ) that was significantly less than that observed in the PFC $(F=2.9, p<0.005$, as determined by two-way repeated-measures ANOVA).

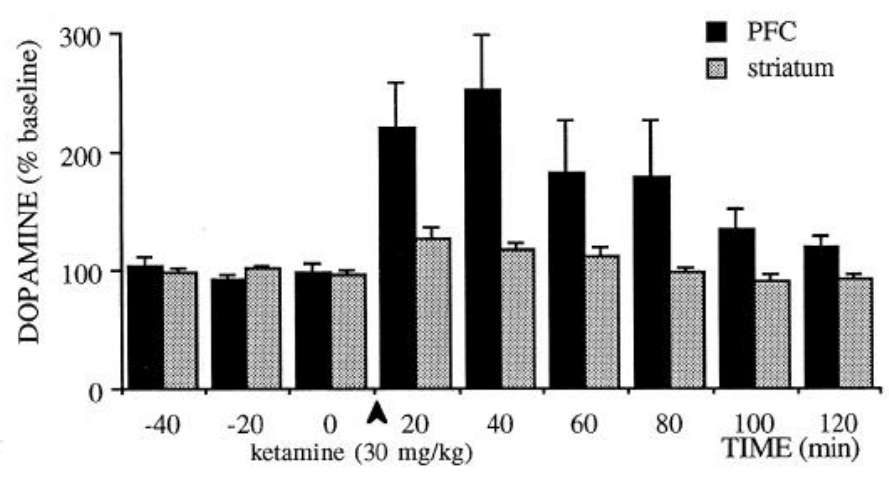

Figure 3. Effect of $30 \mathrm{mg} / \mathrm{kg}$ ketamine on the release of dopamine in the PFC and striatum of freely moving rats. The ordinate represents extracellular levels of dopamine expressed as a percentage of baseline values (mean \pm SEM of 3 samples before drug administration). Ketamine was injected after the collection of the sample at time $0 \mathrm{~min}$. Ketamine produced a significantly higher increase in the release of dopamine over time in the PFC compared with the striatum $(p<0.01$, as determined by two-way repeated-measures ANOVA).

\section{Effect of ketamine on spatial delayed alternation performance in dopamine antagonist-pretreated rats}

To examine the role of increased dopamine neurotransmission on the impairment of spatial delayed alternation by ketamine, animals were treated with several subtypes of dopamine receptor antagonists before receiving $30 \mathrm{mg} / \mathrm{kg}$ ketamine (Fig. 4). Control animals received an injection of saline before ketamine administration. Pretreatment with haloperidol $(0.1 \mathrm{mg} / \mathrm{kg})$ significantly reversed the deficit induced by ketamine $\left(F_{(1,13)}=31.46, p<\right.$ $0.001, n=5$ ) compared with control animals. Pretreatment with raclopride, a D2 $>$ D3 receptor antagonist (Chipkin et al., 1988; Sokoloff et al., 1990), at $0.1 \mathrm{mg} / \mathrm{kg}\left(F_{(1,13)}=1.48, p>0.05, n=\right.$ 5) and $0.5 \mathrm{mg} / \mathrm{kg}\left(F_{(1,17)}=29.34, p<0.001, n=9\right)$ partially reversed the disruptive effect of ketamine on spatial delayed alternation. On the other hand, pretreatment with the D1 receptor antagonist SCH-23390 $(0.1 \mathrm{mg} / \mathrm{kg})$ did not alter the ketamineinduced decrease in percent correct choices $\left(F_{(1,16)}=3.23, p>\right.$ $0.05, n=8$ ).

Figure 5 demonstrates the effect of dopamine antagonists on the spatial delayed alternation when injected alone. These antagonists did not produce a significant effect of their own on this task [haloperidol $(0.1 \mathrm{mg} / \mathrm{kg}): F_{(1,12)}=0.01, p>0.05, n=5$; raclopride $(0.1 \mathrm{mg} / \mathrm{kg}): F_{(1,12)}=1.48, p>0.05, n=5$; raclopride $(0.5$ $\mathrm{mg} / \mathrm{kg}): F_{(1,12)}=2.28, p>0.05, n=5$; SCH-23390 $(0.1 \mathrm{mg} / \mathrm{kg}):$ $\left.F_{(1,14)}=2.28, p>0.05, n=7\right]$.

\section{Effect of various drug treatments on the running time of rats in the T-maze during spatial delayed alternation performance}

Treatment with ketamine $(30 \mathrm{mg} / \mathrm{kg})$ or MK- $801(0.5 \mathrm{mg} / \mathrm{kg})$ failed to produce a significant change in the time the animal took to run between the main arm and the end of one of the goal arms when compared with the saline-treated control group (Table 1). Pretreatment with haloperidol $(0.1 \mathrm{mg} / \mathrm{kg})$, raclopride $(0.5 \mathrm{mg} /$ $\mathrm{kg})$, or SCH-23390 $(0.1 \mathrm{mg} / \mathrm{kg})$ produced a similar running time as after injection of ketamine or saline.

\section{DISCUSSION}

In the present study, the noncompetitive NMDA antagonists ketamine and MK-801 dose-dependently impaired the performance of spatial delayed alternation. This impairment was reduced by the dopamine antagonists haloperidol and raclopride. 
Figure 4. Effect of ketamine $(30 \mathrm{mg} / \mathrm{kg})$ on spatial delayed alternation performance in rats pretreated with saline or various dopamine receptor antagonists. Each animal received 10 trials/d, and the mean $( \pm$ SEM) percentage of correct responses per session is presented. The trials were performed with a delay of $10 \mathrm{sec}$. The values in parentheses represent the doses in $\mathrm{mg} / \mathrm{kg}$. Raclopride (Rac) and haloperidol ( $\mathrm{Hal}$ ) were injected 15 min before ketamine (Ket) in groups designated as Rac/Ket and $\mathrm{Hal} / \mathrm{Ket}$, respectively. $\mathrm{SCH}-23390(\mathrm{SCH})$ was given $5 \mathrm{~min}$ before ketamine in the group designated $\mathrm{SCH} / \mathrm{Ket}$. Pretreatment with raclopride or haloperidol produced a significant reversal of ketamineinduced decrease in percent correct choice in saline-treated rats. The data from animals treated with saline (far left bar) are indicated for the purpose of comparison only $\left({ }^{*} p<\right.$ $0.05,{ }^{* *} p<0.01$ compared with the saline/ Ket group).

This finding, taken together with the increase in dopamine release in the PFC by $30 \mathrm{mg} / \mathrm{kg}$ ketamine, strongly suggests that activation of dopamine neurotransmission contributes, at least in part, to the impairment of PFC function by NMDA antagonists.

\section{Spatial delayed alternation and the role of excitatory amino acids}

A plethora of evidence has implicated the PFC in the pathophysiology of schizophrenia and other cognitive disorders (Weinberger, 1987; Akbarian et al., 1995). Hence, there has been enormous interest in the cellular and neurochemical basis of cognitive functions associated with the PFC. In laboratory animals, the most common behavioral paradigms for assessing PFC function are delayed alternation response tasks, which index an animal's ability to use representational memory (i.e., internalized knowledge) to guide behavior in the absence of informative external cues (Mishkin and Pribram, 1955; Goldman-Rakic, 1987). The capacity to perform delayed response tasks depends on the bilateral integrity of the dorsolateral PFC in the primate and the medial PFC in the rat (Jacobsen, 1936; Harlow et al., 1952; Gross and Weiskrantz, 1964; Mishkin, 1964; Goldman and Rosvold,

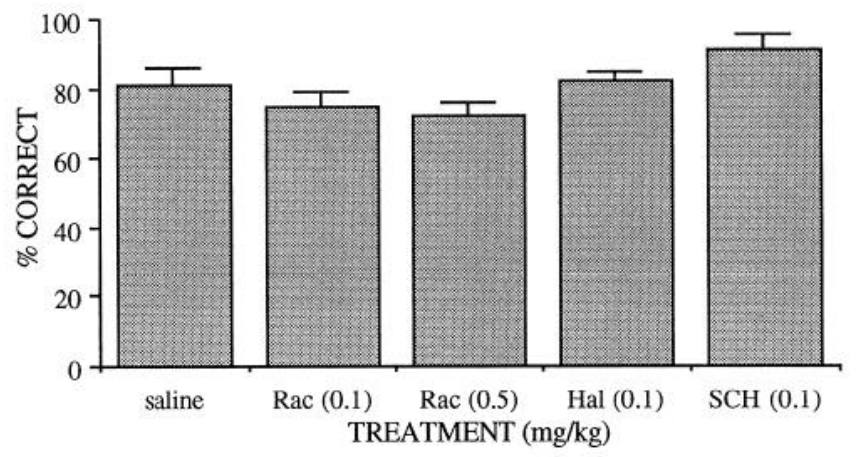

Figure 5. Effect of dopamine receptor antagonists haloperidol ( $\mathrm{Hal})$, raclopride (Rac), and SCH-23390 (SCH) on performance of rats on spatial delayed alternation as assessed by the percent correct choice (mean \pm SEM) reached. Each animal received 10 trials/d with an intertrial interval of $10 \mathrm{sec}$. The rats were trained until the criterion of $80 \%$ correct choices on two consecutive days was reached. The doses (mg/kg, i.p.) are indicated in parentheses. None of the antagonists produced a significant change in spatial delayed alternation performance compared with the saline-treated rats.
1970; Butters et al., 1972; Passingham, 1975; Brito et al., 1982; Wilcott and Xuemei, 1990; Freeman and Stanton, 1992).

The present finding that MK-801 and ketamine impaired spatial delayed alternation performance strongly implicates excitatory amino acid neurotransmission at the NMDA receptor in the capacity to perform working memory-related tasks. This finding is in line with clinical studies showing that ketamine and phencyclidine impair the ability of individuals to use internalized representations for problem-solving strategies (Ghoneim et al., 1985; Javitt and Zukin, 1991; Krystal et al., 1994). In addition, studies in the rodent have indicated that ketamine and other NMDA antagonists disrupt the performance of behavioral paradigms that involve spatial memory, attention, and learning. These include passive avoidance learning, prepulse inhibition of acoustic startle response, the Morris water maze, and the eight-arm radial maze (Morris et al., 1986; Parada-Turska and Turski, 1990; Shapiro and Caramano, 1990; Wesierska et al., 1990; Uchihashi et al., 1994).

Additional studies have reported that ketamine attenuates sensory perception (Oye et al., 1992). This may indicate that the impairment of spatial delayed alternation by NMDA antagonists is not an impairment of working memory per se but, rather, is produced by a general reduction or distortion of sensory input that would affect the performance of any spatial-related task.

Table 1. Effect of various drugs on the running time of rats during spatial delayed performance in a T-maze

\begin{tabular}{llrl}
$\begin{array}{l}\text { Experiment } \\
\text { No. }\end{array}$ & Treatment (mg/kg) & $\begin{array}{l}\text { Running } \\
\text { time (sec) } \\
\text { mean } \pm \text { SEM }\end{array}$ \\
\hline 1 & Saline & 15 & $2.15 \pm 0.09$ \\
2 & Ketamine (30) & 10 & $2.34 \pm 0.12$ \\
3 & MK-801 (0.5) & 6 & $1.95 \pm 0.10$ \\
4 & Haloperidol (0.1) & 5 & $2.20 \pm 0.14$ \\
5 & Raclopride (0.5) & 5 & $2.48 \pm 0.37$ \\
6 & SCH-23390 (0.1) & 7 & $2.28 \pm 0.14$ \\
7 & Haloperidol (0.1) + Ketamine (30) & 5 & $2.47 \pm 0.12$ \\
8 & Raclopride (0.5) + Ketamine (30) & 9 & $2.09 \pm 0.07$ \\
9 & SCH-23390 (0.1) + Ketamine (30) & 8 & $2.50 \pm 0.13$
\end{tabular}

The time (sec) the animal took to run between the main arm and the end of one of the goal arms was recorded in all animals during spatial delayed alternation performance. All time measures are mean \pm SEM. None of the drug treatments produced a significant effect on running time compared with the saline-treated control group. 
However, the doses of ketamine and MK-801 that impaired the spatial delayed alternation performance did not disturb the performance of the spatial discrimination task, a paradigm that used the same $T$-maze as the spatial delayed alternation but did not involve a delay or alternation. This finding suggests that the NMDA antagonist-induced impairment of spatial delayed alternation cannot be attributed primarily to reduced sensory perception; rather, a disruption in sensory integration and associative functions might have occurred.

\section{Possible mechanisms of actions of ketamine}

Ketamine has been reported to have direct and indirect actions on several neurotransmitter systems other than excitatory amino acids. For example, ketamine is an acetylcholinesterase inhibitor (Cohen et al., 1974) and has affinities for the $\sigma$ and $\mu$ opiate receptors (Smith et al,, 1980) and monoamine transporters (Smith et al., 1981). Thus, it can be suggested that the ability of ketamine to impair spatial delayed alternation is attributable to the action of this drug on sites other than the NMDA receptor. However, the affinity of ketamine for these other sites is orders of magnitude lower than its affinity for the NMDA receptor (Thomson et al,, 1985). Although non-NMDA actions of ketamine may account for the anesthetic doses $(200-400 \mathrm{mg} / \mathrm{kg})$ of this drug, it is unlikely that the lower subanesthetic doses used here $(10-30 \mathrm{mg} / \mathrm{kg}$ ) would have considerable actions on non-NMDA sites. The fact that the more selective NMDA antagonist MK-801 had similar effects as ketamine further supports the idea that blockade of NMDA receptors was the primary mechanism by which ketamine exerted its disruptive effect on spatial delayed alternation performance. Nevertheless, the role of other receptor sites in the behavioral effects of ketamine or MK-801 cannot be disregarded (Clineschmidt et al., 1982; Lapin and Rogawski, 1992; Loscher and Honack, 1992).

Selective activation of dopamine release in the PFC by ketamine, as well as reversal of the behavioral deficits of ketamine by dopamine antagonists, suggests that enhanecment of dopaminergic neurotransmission by ketamine plays a role in the performance decrement of spatial delayed alternation. It is noteworthy that previous studies have indicated that other noncompetitive NMDA antagonists including MK-801 and phencyclidine also preferentially activate dopamine neurotransmission in the PFC (Rao et al., 1989; Wedzony et al., 1993; Hondo et al., 1994). One mechanism by which these antagonists may increase dopamine release in the PFC is by altering the firing rate and pattern of mesocortical dopamine neurons. Electrophysiological studies have reported that NMDA antagonists increase the firing rate of dopamine neurons in the midbrain (French, 1994). However, it is not clear whether these drugs have preferential stimulatory effects on mesocortical dopamine neurons versus nigrostriatal dopamine neurons that project to the striatum (which presumably were not activated by ketamine). Ketamine may also activate feedback loops or local mechanisms that control the release of dopamine in the PFC. For example, blockade of NMDA receptors may reduce the activity of GABA neurons that normally inhibit dopamine release. Attenuation of GABAergic inhibition, in turn, would increase the release of dopamine.

Ketamine and MK-801 administration generally are associated with behavioral symptoms such as hyperlocomotion and stereotypy (Koek et al., 1989; Irifune et al., 1991; Uchihashi et al., 1992), which might affect the performance of the animal in the spatial delayed alternation task. However, the lack of a significant difference in the running time between the ketamine- and saline- treated groups in the present study and the fact that performance in the spatial discrimination task was not affected by ketamine or MK-801 negate the possibility of interference by locomotor activity in the spatial delayed alternation performance of the animals.

\section{Spatial delayed alternation and the role of dopamine}

Several lines of research have suggested that dopamine has a critical role in the associative functions of the PFC. In particular, selective lesions of dopamine afferents to the PFC, in the rat or the primate, disrupt the performance of delayed response-related tasks (Brozoski et al., 1979; Simon et al., 1980; Stam et al., 1989; Roberts et al., 1994). Hence, these studies have concluded that a reduction in dopaminergic neurotransmission in the PFC impairs the proper functioning of this region.

In the present study, it was found that pretreatment with the dopamine antagonist haloperidol, which has affinities for D2, D4 $>$ D1 dopamine receptors, and raclopride, a D2 $>$ D3 dopamine receptor antagonist (Hyttel et al., 1983; Christensen et al., 1984; Kohler et al., 1985; de Paulis et al., 1986; Hall et al., 1986; Memo et al., 1986; Chipkin et al., 1988; Sokoloff et al., 1990), but not the D1 receptor antagonist SCH-23390 (Iorio et al., 1983), reversed the deficit in spatial delayed alternation produced by ketamine. These findings suggest that hyperactivation of dopamine receptors (presumably at the D2 and/or D4 receptor) was involved, at least in part, in the NMDA antagonist-induced impairment of spatial delayed alternation. This idea is supported by the microdialysis data indicating that the dose of ketamine that led to a profound deficit in spatial delayed alternation preferentially increased the release of dopamine in the PFC. Similarly, systemic injection of MK-801, at similar doses used in the present study, has been reported to increase dopamine release in the PFC (Wedzony et al., 1993). Collectively, these data suggest that an activation of dopamine neurotransmission in the PFC also impairs its function (Murphy et al,, 1994).

The dopamine antagonists, when administered alone, did not impair the spatial delayed alternation performance. In fact, administration of SCH-23390 indicated a trend toward improving the performance of this task. This is in contrast with previous reports showing that intracerebral injection of selective D1 receptor antagonists SCH-23390 or SCH-39166 impairs delayed alternation (Sawaguchi and Goldman-Rakic, 1994). However, recent reports indicated that lower doses of D1 antagonists do not produce these results and even may improve PFC function (Williams and Goldman-Rakic, 1995), suggesting that the deficit caused by higher doses of SCH-23390 or SCH-39166 is attributable to nonspecific or local anesthetic properties of these drugs. Nevertheless, the fact that blockade of dopamine receptors (at D1, D2, D3, and D4 sites) did not impair spatial delayed alternation performance at the doses used here suggests that tonic activation of these dopamine receptors does not contribute to the working memory-related cognitive functions of the PFC.

These latter findings are in contrast with neurochemical lesion studies concluding that a reduction in dopaminergic neurotransmission in the PFC impairs its associative functions (Brozoski et al., 1979; Simon et al., 1980; Stam et al., 1989; Roberts et al., 1994). This paradox in the role of dopamine in the PFC may be attributable to several mechanisms. (1) Profound reduction in dopamine neurotransmission, as opposed to selective decreases at specific receptors, is required to impair PFC function. (2) There may be as yet unidentified dopamine receptors that play an important role in associative functions of the PFC for which the antagonists used here do not have an affinity. This is supported by 
electrophysiological studies indicating that in the PFC the postsynaptic response to dopamine is not effectively blocked by known dopamine antagonists (Shi and Bunney, 1994). (3) The long-term reduction of dopamine neurotransmission produced by the neurochemical lesions of dopamine afferents results in adaptive alterations in other neuronal systems, for example, glutamatergic, which in turn impair PFC function. Dopamine terminals in the PFC synapse on dendritic spines, which also receive convergent synaptic input from excitatory, glutamatergic afferents (Smiley et al., 1992; Smiley and Goldman-Rakic, 1993). This synaptic "triad" has been postulated to represent an anatomical substrate for local modulation of excitatory inputs by dopamine. Thus, long-term reduction of this modulation (i.e., after neurochemical lesions of dopamine terminals) may produce, in turn, compensatory changes in glutamatergic neurotransmission at these sites. In fact, long-term blockade of dopamine receptors has been shown to alter the expression of several subtypes of excitatory amino acid receptors (Fitzgerald et al., 1995).

\section{Conclusions}

In the present study, it was demonstrated that the NMDA receptor antagonists ketamine and MK-801 impaired the performance of a spatial delayed alternation task without affecting the performance of a spatial discrimination task, suggesting that tonic activation of NMDA receptors contributes to the cognitive functions associated with the PFC. In contrast, several dopamine receptor antagonists with affinities at D1, D2, D3, and D4 dopamine receptors did not affect the spatial delayed alternation, suggesting that tonic activation of the these dopamine receptors does not contribute to working memory-related functions of the PFC. However, the dopamine receptor antagonists haloperidol and raclopride reversed the deficit produced by ketamine. This finding, taken together with the microdialysis data presented here that ketamine induced a preferential increase in the release of dopamine in the PFC, strongly implies that activation of dopamine neurotransmission played a role in the impairment of spatial delayed alternation produced by NMDA antagonists. Hence, considering the previous neurochemical lesion studies, it appears that both acute excess and chronic deficiency in dopamine neurotransmission disrupt the associative functions of the PFC.

\section{REFERENCES}

Akbarian S, Kim JJ, Potkin SG, Hagman JO, Tafazzoli A, Bunney WE, Jones EG (1995) Gene expression for glutamic acid decarboxylase is reduced without loss of neurons in prefrontal cortex of schizophrenics. Arch Gen Psychiatry 52:258-266.

Brito G, Thomas G, Davis B, Gingold S (1982) Prelimbic cortex, mediodorsal thalamus, septum, and delayed alternation in rats. Exp Brain Res 46:52-58.

Brozoski T, Brown R, Rosvold H, Goldman P (1979) Cognitive deficits produced by regional depletion of dopamine in prefrontal cortex of rhesus monkcy. Science 205:929-932.

Butters N, Pandya D, Stein D, Rosen J (1972) A search for the spatial engram within the frontal lobes of monkeys. Acta Neurobiol Exp Warsaw 32:305-329.

Chipkin R, Iorio L, Coffin V, McQuade R, Berger J, Barnett A (1988) Pharmacological profile of SCH 39166: a dopamine D1 selective benzonaphthaline with potent antipsychotic activity. J Pharmacol Exp Ther 247:1093-1102.

Christensen A, Arnt V, Hyttel J, Larsen J, Svendsen O (1984) Pharmacological effects of a specific dopamine D1-antagonist SCH 23390 in comparison with neuroleptics. Life Sci 34:1529-1540.

Clineschmidt BV, Martin GE, Bunting PR, Papp NL (1982) Central sympathomimetic activity of (+)-5-methyl-10,11-dihydro-5H-dibenzo(a,d)-cyclohepten-5,10-imine (MK 801), a substance with potent anticonvulsant, central sympathomimetic and apparent anxiolytic properties. Drug Dev Res 2:135-145.
Cohen M, Chan S, Bhargava H, Trevor A (1974) Inhibition of mammalian brain acetylcholinesterase by ketamine. Biochem Pharmacol 23:1647-1652.

De Paulis T, Kumar Y, Johansson L, Hall H, Sallemark M, Aneby-Moller K, Ogren S-O (1986) Potential neuroleptic agent 4: chemical behavioral pharmacology, and inhibition of $\left({ }^{3} \mathrm{H}\right)$-spiperone binding of 3,5disubstitute $\quad N$-((1-ethyl-2-pyrrolidinyl)methyl)-6-methoxy-salicylamides. J Med Chem 29:61-69.

Fitzgerald L, Deutch A, Gasic G, Heinemann S, Nestler E (1995) Regulation of cortical and subcortical glutamate receptor subunit expression by antipsychotic drugs. J Neurosci 15:2453-2461.

Freeman JJ, Stanton M (1992) Medial prefrontal cortex lesions and spatial delayed alternation in the developing rat: recovery or sparing? Behav Neurosci 106:924-932.

French E (1994) Phencyclidine and the midbrain dopamine system: electrophysiology and behavior. Neurotoxicol 'T'eratol 16:355-362.

Fuster J (1980) The prefrontal cortex. New York: Raven.

Ghoneim M, Hinrichs J, Mewaldt S, Petersen R (1985) Ketamine: behavioral effects of subanesthetic doses. J Clin Psychopharmacol 5:70-77.

Goldman P, Rosvold H (1970) Localization of function within the dorsolateral prefrontal cortex of the rhesus monkey. Exp Neurol 27:291-304.

Goldman-Rakic PS (1987) Circuitry of the prefrontal cortex and the regulation of behaviour by representational knowledge. In: Handbook of physiology (Plum F, Mountcastle V, eds), pp 373-417. Bethesda, MD: American Physiological Society.

Goldman-Rakic PS (1991) Prefrontal cortical dysfunction in schizophrenia: the relevance of working memory. In: Psychopathology and the brain (Carroll BJ, Barrett JE, eds), pp 72-91. New York: Raven.

Gross C, Weiskrantz L (1964) Some changes in behavior produced by lateral frontal lesions in the macaque. In: The frontal granular cortex and behavior (Warren JM, Akert K, eds), pp 74-101. New York: McGraw-Hill.

Hall H, Sallemark M, Jerning E (1986) Effects of remoxipride and some related new substituted saclicymides on rat brain receptor. Acta Pharmacol Toxicol 58:61-70.

Harlow H, Davis R, Settlage P, Meyer D (1952) Analysis of frontal and posterior association syndromes in brain-damaged monkeys. J Comp Physiol Psychol 45:419-429.

Hondo H, Yonezawa Y, Nakahara T, Nakamura KHM, Mirano M, Uchimura H, Tashiro N (1994) Effects of phencyclidine on dopamine release in the rat prefrontal cortex: an in vivo microdialysis study. Brain Res 633:337-342

Hyttel J (1983) SCH 23390: the first selective dopamine D1 antagonist. Eur J Pharmacol 91:153-154.

Iorio L, Barnett A, Leitz F, House V, Korduba C (1983) SCH 23390, a potential benzazepine antipsychotic with unique interactions on dopaminergic systems. J Pharmacol Exp Ther 226:462-468.

Irifune M, Shimizu T, Nomoto M (1991) Ketamine-induced hyperlocomotion associated with alternation of presynaptic components of dopamine neurons in the nucleus accumbens of mice. Pharmacol Biochem Behav 40:399-407.

Jacobsen C (1936) Studies of cerebral function in primates. Comp Psychol Monogr 13:1-68.

Javitt D, Zukin S (1991) Recent advances in phencyclidine model of schizophrenia. Am J Psychiatry 148:1-10.

Jedema H, Moghaddam B (1996) Characterization of excitatory amino acid modulation of dopamine release in the prefrontal cortex of conscious rats. J Neurochem, in press.

Koek W, Colpaert F, Woods J, Kamenka J-M (1989) The phencyclidine (PCP) analog $N$-[1-(2-benzo(b)thiophenyl)cyclohexyl]piperidine shares cocaine-like but not other characteristic behavior effects with PCP, ketamine and MK-801. J Pharmacol Exp Ther 250:1019-1027.

Kohler C, Hall H, Orgren S-O, Grawell L (1985) Specific in vitro and in vivo binding of $\left({ }^{3} \mathrm{H}\right)$-raclopride: a potent substituted benzamidine drug with high affinity for dopamine D2 receptors in the rat brain. Biochem Pharmacol 34:2251-2259.

Krystal J, Karper L, Seibyl J, Freeman G, Delaney R, Bremner J, Heninger G, Bowers M, Charney D (1994) Subanesthetic effects of the noncompetitive NMDA antagonist, ketamine, in humans. Arch Gen Psychiatry 51:199-214.

Lapin IP, Rogawski MA (1992) Muscarinic antagonists attenuate dizocilpine-induced hypermotility in mice. Life Sci 50:59-64. 
Loscher W, Honack D (1992) The behavioural effects of MK-801 in rats: involvement of dopaminergic, scrotoninergic and noradrenergic systems. Eur J Pharmacol 215:199-208.

McCarthy G, Blamire A, Puce A, Nobre A, Bloch G, Hyder F, GoldmanRakic PS, Shulman R (1994) Functional magnetic resonance imaging of human prefrontal cortex activation during a spatial working memory task. Proc Natl Acad Sci USA 91:8690-8694.

Memo M, Missale C, Carruba M, Spano P (1986) Pharmacology and biochemistry of dopamine receptors in the central nervous system and peripheral tissue. J Neural Transm 22:19-32.

Mishkin M (1964) Preservation of central sets after frontal lesions in monkeys. In: The frontal granular cortex and behavior (Warren JM, Akert K, eds), pp 219-241. New York: McGraw-Hill.

Mishkin M, Pribram K (1955) Analysis of the effects of frontal lesions in monkey. I. Variations on delayed alternation. J Comp Physiol Psychol 48:492-495.

Morris R, Anderson E, Lynch G, Baudry M (1986) Selective impairment of learning and blockade of long term potentiation by an $\mathrm{N}$-methyl-Daspartate antagonist, AP5. Nature 319:774-776.

Murphy BL, Roth RH, Arnsten AFT (1994) The effect of FG 7142 on prefrontal cortex dopamine and spatial working memory in rat and monkey. Soc Neurosci Abstr 24:416-421.

Oye N, Paulsen O, Maurset A (1992) Effects of ketamine on sensory perception: evidence for a role of $N$-methyl-D-aspartate receptors. J Pharmacol Exp Ther 260:1209-1213.

Parada-Turska J, Turski W (1990) Excitatory amino acid antagonists and memory: effect of drugs acting at $N$-methyl-D-aspartate receptors in learning and memory tasks. Neuropharmacology 29:1111-1116.

Parks S, Holzman P (1992) Schizophrenics show spatial working memory deficits. Arch Gen Psychiatry 49:975-982.

Passingham R (1975) Delayed matching after selective prefrontal lesions in monkeys (Macaca mulatta). Brain Res 92:89-102.

Paxinos G, Watson C (1982) The brain in stereotaxic coordinates. New York: Academic.

Rao T, Kim H, Lehman J, Martin L, Wood P (1989) Differential effects of phencyclidine (PCP) and ketamine on mesocortical and mesostriatal dopamine release in vivo. Life Sci 45:1065-1072.

Roberts A, De Salvia M, Wilkinson L, Collins P, Muir J, Fveritt B, Robbins T (1994) 6-Hydroxydopamine lesions of the prefrontal cortex in monkeys enhance performance on an analog of the Wisconsin Card Sort Test: possible interactions with subcortical dopamine. J Neurosci 14:2531-2544.

Sawaguchi T, Goldman-Rakic PS (1991) D1 dopamine receptors in prefrontal cortex: involvement in working memory. Science 251:947-950.

Sawaguchi T, Goldman-Rakic PS (1994) The role of D1 dopamine receptor in working memory: local injections of dopamine antagonists into the prefrontal cortex of rhesus monkeys performing an oculomotor delayed-response task. J Neurophysiol 71:515-528.

Shapiro M, Caramano Z (1990) NMDA antagonist MK-801 impairs acquisition but not performance of spatial working and reference memory. Psychobiology 18:231-243.

Shi W-X, Bunney B (1994) Dopamine-induced depolarization of medial prefrontal cortical neurons. Soc Neurosci Abstr 20:1354.

Simon H, Scatton B, Le Moal M (1980) Dopaminergic A10 neurons are involved in cognitive functions. Nature 286:150-151.

Smiley J, Goldman-Rakic PS (1993) Heterogeneous targets of dopamine synapses in monkey prefrontal cortex demonstrated by serial section electron microscopy: a laminar analysis using the silver-enhanced diaminobenzidine sulfide (SEDS) immunolabcling technique. Cerebral Cortex 3:223-238.

Smiley J, Williams S, Szigeti K, Goldman-Rakic PS (1992) Light and electron microscopic characterization of dopamine-immunoreactive axons in human cerebral cortex. J Comp Neurol 321:325-335.

Smiley JF, Levey A, Ciliax B, Goldman-Rakic PS (1994) D1 dopamine receptor immunoreactivity in human and monkey cerebral cortex: predominant and extrasynaptic localization in dendritic spines. Proc Natl Acad Sci USA 91:5720-5724.

Smith D, Azzaro A, Zaldivar S, Palmer S, Lee H (1981) Properties of the optical isomers and metabolites of ketamine on the high affinity transport and catabolism of monoamines. Neuropharmacology 20:391-396.

Smith D, Westfall D, Adams J (1980) Ketamine interacts with opiate receptors as an agonist (Abstr). Anesthesiology 53A.

Sokoloff P, Giros B, Martres M-P, Bouthenet M-L, Schwartz J-C (1990) Molecular cloning and characterization of a novel dopamine receptor (D3) as a target for neuroleptics. Nature 347:146-151.

Stam C, de Bruin J, van Haelst A, van der Gugten J, Kalsbeck A (1989) Influence of the mesocortical dopaminergic system on activity, food hoarding, social-agonistic behavior, and spatial delayed alternation in male rats. Behav Neurosci 103:24-35.

Stuss D, Benson D (1983) Frontal lobe lesions and behavior. Localization in neuropsychology (Kertesz A, ed), pp 429-454. New York: Academic.

Thomson A, West D, Lodge D (1985) An $N$-methyl-D-aspartate receptor-mediated synapse in rat cerebral cortex: a site of action of ketamine? Nature 313:479-481.

Taylor MA, Abrams R (1984) Cognitive impairment in schizophrenia. Am J Psychiatry 141:196-201.

Uchihashi Y, Kuribara H, Isa Y, Morita T, Sato T (1994) The disruptive effects of ketamine on passive avoidance learning in mice: involvement of dopaminergic mechanisms. Psychopharmacology 116:40-44.

Uchihashi Y, Kuribara H, Morita T, Fujita T (1993) The repeated administration of ketamine induces an enhancement of its stimulant action in mice. Jpn $\mathbf{J}$ Pharmacol 61:149-151.

Uchihashi Y, Kuribara H, Tadokoro S (1992) Assessment of the ambulation-increasing effect of ketamine hy coadministration with centralacting drugs in mice. Jpn J Pharmacol 60:25-31.

Wedzony K, Klimek V, Golembiowska K (1993) MK-801 elevates the extracellular concentration of dopamine in the rat prefrontal cortex and increases the density of striatal dopamine D1 receptors. Brain Res $622: 325-329$.

Weinberger D (1987) Implication of normal brain development for the pathogenesis of schizophrenia. Arch Gen Psychiatry 44:660-669.

Weinberger D, Berman K, Zec R (1986) Physiological dysfunction of dorsolateral prefrontal cortex in schizophrenia. I. Regional cerebral blood flow (rCBF) evidence. Arch Gen Psychiatry 43:114-125.

Wesierska M, Macias-Gonzalez R, Bures J (1990) Differential effects of ketamine on the reference and working memory versions of the Morris water maze task. Behav Neurosci 104:74-83.

Wilcott R, Xuemei Q (1990) Delayed response, preoperative overtraining, and prefrontal lesions in the rat. Behav Neural Biol 53:393-401.

Williams G, Goldman-Rakic PS (1995) Iontophoretic application of D1 receptor antagonists on prefrontal pyramidal neurons enhances neuronal memory fields associated with delayed response performance. Proc Natl Acad Sci USA 92:1111-1121. 